\title{
O ponto perdido na trama do desenvolvimento da cotonicultura em Mato Grosso
}

\section{The weft lost in development of cotton crop in Mato Grosso}

Alexandre Magno de Melo Faria - Doutor em Desenvolvimento Socioambiental, NAEA/UFPA, 2008; professor Adjunto II da Faculdade de Economia da Universidade Federal de Mato Grosso (FE/UFMT). E-mail: dr.melofaria@gmail.com

\section{Resumo}

A cotonicultura brasileira está espacialmente concentrada no estado de Mato Grosso desde a safra de 1999. A estrutura produtiva atual é dominada por grandes empreendimentos capitalistas. Contudo, entre as décadas de 1930 e 1980 a cotonicultura no atual Mato Grosso representava menos de $1 \%$ da produção nacional e era desenvolvida pelo campesinato em áreas inferiores a 30 hectares. A produtividade da terra e do trabalho estavam abaixo da média nacional e mundial neste ramo produtivo. Investimentos públicos realizados no início da década de 1980 elevaram substancialmente a produtividade da terra e do trabalho na cotonicultura camponesa, com relevantes impactos na geração de renda e na inclusão social. Contudo, o projeto não recebeu continuidade e as políticas públicas passaram a favorecer o grande capital agrário no início da década de 1990, ajustadas com a corrente neoliberal que se implantou no Brasil. O modelo atual de produção privilegia a concentração produtiva em áreas acima de 2.800 hectares, negligenciando milhares de famílias camponesas que poderiam fornecer pluma de alta qualidade aos mercados nacional e internacional e gerar desenvolvimento regional. Perdeu-se uma importante oportunidade de tecer o tecido do desenvolvimento de forma mais equitativa.

\section{Palavras-chave}

Algodão. Cotonicultura. Campesinato. Mato Grosso.

\begin{abstract}
The cotton crop is spatially concentrated in the Brazilian state of Mato Grosso from 1999. The current productive structure is dominated by large capitalist enterprises. However, between the 1930 and 1980 cotton production in Mato Grosso current represented less than 1\% of national production and was developed by peasants in areas smaller than 30 hectares. The productivity of land and labor were below the national average and global production in this branch. Public investments made in the early 1980 substantially increased the productivity of land and peasant labor in cotton farming, with significant impacts on income generation and social inclusion. However, the project did not receive continuity and agricultural policy passed to favor the large agrarian capital in the early 1990s, adjusted to the current neoliberal was implanted in Brazil. The current model of production favors the concentration of production in areas larger than 2,800 acres, neglecting thousands of peasant families that could provide high quality feather to national and international markets and generate regional development. It missed an important opportunity to weave the fabric of development more equitably.
\end{abstract}

\section{Keywords}

Cotton. Cotton Crop. Peasants. Mato Grosso. 


\section{INTRODUÇÃO}

A cotonicultura iniciou sua trajetória em solo mato-grossense ainda na primeira metade do século passado, sendo que o primeiro registro é datado de 1933, quando da chegada a Mato Grosso do agricultor Liberato Barrozo, trazendo os primeiros 1.200 quilos de sementes melhoradas do algodão herbáceo oriundas do estado norte-americano do Texas ${ }^{1}$. Papel de destaque no início da evolução desta cultura coube ao agricultor Elias Medeiros, apoiando a produção e expansão da cultura em Mato Grosso, inicialmente na região de Três Lagoas, atual Mato Grosso do Sul. A partir de 1962, Elias Medeiros passou a morar em Rondonópolis, produzindo e incentivando o cultivo do algodão nas atuais regiões de São José do Povo, Nova Galileia, Jaciara, Pedra Preta e Juscimeira, na região Sudeste do atual Mato Grosso (PROALMAT, 2007).

No Censo Agropecuário de 1940 há o registro de 2.145 hectares de cotonicultura em Mato Grosso ${ }^{2}$, de um total de 2.412.484 hectares desta cultura no Brasil. A produção mato-grossense foi de 1.330 toneladas, com produtividade de 620 quilos/hectare. A produção nacional naquela safra foi de 1.562.307 toneladas, com rendimento de 648 quilos/hectare. A produção de pluma em Mato Grosso representava apenas $0,08 \%$ da pluma brasileira (IBGE, 1940). No Censo Agropecuário de 1950 a área destinada ao cultivo de algodão foi de 2.699 hectares em Mato Grosso, de um total de 2.689.185 hectares desta cultura no Brasil. A produção mato-grossense foi de 3.370 toneladas, com produtividade de 1.250 quilos/hectare. A produção nacional naquela safra foi de 1.190.909 toneladas, com rendimento de 443 quilos/hectare. A produção de pluma em Mato Grosso representava apenas 0,28\% da pluma brasileira (IBGE, 1950).

$\mathrm{Na}$ década seguinte, foi registrada no Censo Agropecuário de 1960 a área de 14.718 hectares destinados ao cultivo de algodão em Mato Grosso, de um total de 2.930.361 hectares desta cultura no Brasil. A produção matogrossense foi de 13.904 toneladas, com produtividade de 945 quilos/hectare. A produção nacional naquela safra foi de 1.609.275 toneladas, com rendimento de 550 quilos/hectare. A produção de pluma em Mato Grosso representava apenas 0,92\% da pluma brasileira (IBGE, 1960). Em 1970, a área de cotonicultura já havia alcançado 105.700 hectares em Mato Grosso, notadamente na sua porção Meridional, na região de Dourados, Fátima do Sul, Glória de Dourados, Naviraí, Caarapó e Bataiporã, que concentravam sozinhos $62 \%$ da área cultivada com algodão. A produção total foi de 106.334 toneladas, com produtividade de 1.006

\footnotetext{
A variedade cultivada era a Texas 7111.

Quando se refere a "Mato Grosso" nos Censos Agropecuários de 1940, 1950, 1960 e 1970 o atual território de Mato Grosso do Sul está incluído.
} 
quilos por hectare, representando $8,3 \%$ da produção nacional. Havia 6.416 estabelecimentos produzindo algodão como atividade econômica principal. Destes, 4.001 controlavam menos de 10 hectares, produzindo em áreas médias de 5 hectares. Outros 2.324 estabelecimentos produziam em áreas médias de 24 hectares, no grupo de área entre 10 e 100 hectares. Os estabelecimentos menores de 100 hectares correspondiam a 98\% das unidades de produção com especialização em cotonicultura, controlando $71 \%$ dos campos de algodão. Havia um grupo de médios e grandes produtores com áreas acima de 100 hectares, que representavam apenas $2 \%$ dos estabelecimentos, controlando $29 \%$ do espaço (IBGE, 1970). Uma produção típica de algodão era realizada em uma área de 16 hectares, demonstrando que a escala de eficiência era facilmente encontrada pela agricultura familiar.

Os dados censitários da agropecuária até o ano de 1970 agregam os atuais estados de Mato Grosso e Mato Grosso do Sul. Considerando apenas o território do atual Mato Grosso, a área destinada à cotonicultura em 1970 foi de apenas 6.332 hectares, representando $6 \%$ da área total desta cultura naquele estado. Em relação à área total de produção no Brasil, a cotonicultura mato-grossense representava apenas $0,4 \%$ de participação no espaço cotonícola nacional. Destes, 5.888 hectares $(93 \%)$ ocorreram na região de Sudeste mato-grossense, onde o polo principal era Rondonópolis, além de Jaciara, Poxoréo, Guiratinga, Dom Aquino e Itiquira, resultado das ações de difusão da atividade desenvolvida por Elias Medeiros. Até o início da década de 1980 esta região ficou conhecida como "Rainha do Algodão" pela concentração produtiva verificada. Os registros agrários indicam a hegemonia dos pequenos produtores familiares neste período (MATO GROSSO, 2006).

\section{UM NOVO OLHAR SOBRE A COTONICULTURA FAMILIAR DA DÉCADA DE 1980}

O registro da série histórica de produção de algodão em Mato Grosso pela CONAB inicia-se em $1979^{3}$, com 5.200 hectares plantados e uma produção de 1.200 mil toneladas de pluma de algodão herbáceo, apresentando uma produtividade de apenas 230 quilos por hectare (CONAB, 2005). Note-se que a área plantada em 1979 é ligeiramente inferior à área cultiva em 1970. Neste

\footnotetext{
E $1^{\circ}$ de janeiro de 1979 ocorreu a separação oficial dos estados de Mato Grosso e Mato Grosso do Sul. Desta forma, a maior produtividade da cotonicultura em Mato Grosso antes de 1979 estava enviesada positivamente pela maior produtividade que vigorava no atual Mato Grosso do Sul.
} 
primeiro período, a estrutura produtiva não tem peso relativo importante e sua dinâmica tem pouca influência sobre expansão do produto regional. Variáveis macroeconômicas estritamente de mercado e a ausência de uma logística interna não ofereciam condições satisfatórias de Mato Grosso integrar o grupo de espaços especializados em cotonicultura.

O Censo Agropecuário de 1980 confirma a baixa expansão da atividade em Mato Grosso. Foram registrados apenas 211 estabelecimentos produtores de algodão, com área média de 29 hectares. A área total cultivada foi de 6.127 hectares, praticamente a mesma dimensão verificada em 1970. Os estabelecimentos com áreas menores de 100 hectares representam 95\% das unidades de produção, controlando $62 \%$ da área total. Há uma ligeira elevação na escala entre os produtores no grupo entre 10 e 100 hectares, que produziam em áreas médias de 24 hectares em 1970 passaram a cultivar 32 hectares em 1980. Não se verificaram áreas acima de 1.000 hectares e apenas 11 produtores com escala acima de 100 hectares. A produção foi de 1.367 toneladas, representando $0,12 \%$ do algodão nacional, com produtividade de apenas 223 quilos por hectare. $\mathrm{Na}$ safra de 1980 a região sudeste de Mato Grosso continuou com a maior concentração de lavouras de algodão, com 3.197 hectares (52\% da área total), com destaque para os municípios de Rondonópolis (2.426 hectares) e Pedra Preta (502 hectares). A região Sudoeste também apresentou uma importante lavoura, com 2.336 hectares (38\% do total), com destaque para Cáceres com 1.920 hectares plantados (IBGE, 1980).

Tabela 1: Áreas de cotonicultura no censo de 1980: Mato Grosso.

\begin{tabular}{l|c|c|c|c|c}
\hline \multirow{2}{*}{ Dados estruturais } & \multicolumn{6}{|c}{ Grupos de área (hectares) } \\
\cline { 2 - 6 } & $0 \dashv 10$ & $10 \dashv 100$ & $100-1.000$ & $1.000 \dashv 10.000$ & Total \\
\hline UPA (unidades) & 98 & 102 & 11 & - & 211 \\
\hline UPA (\%) & 46 & 48 & 6 & - & 100 \\
\hline Área (hec.) & 500 & 3.292 & 2.335 & - & 6.127 \\
\hline Áreas (\%) & 8 & 54 & 38 & - & 100 \\
\hline Área Média (hec.) & 5 & 32 & 212 & - & 29 \\
\hline
\end{tabular}

Fonte: IBGE, Censo Agropecuário de 1980.

Nota: UPA refere-se à Unidade de Produção Agrícola.

Considerando que naquele momento não havia tecnologia mecânica disponível para empregar nos processos de preparação do solo, plantio, tratos culturais e principalmente na colheita, a força de trabalho é que representava o principal meio da força produtiva. Não obstante, a concentração das unidades 
em estratos de área inferiores a 100 hectares confirmam que é o campesinato a estrutura socioprodutiva hegemônica na produção de fibras vegetais derivadas do algodoeiro desde a sua implantação em Mato Grosso. Simplesmente por não haver métodos capazes de elevar a força produtiva pela substituição de máquinas e capital constante por capital variável é que os patronais não se interessam em alocar recursos na cotonicultura mato-grossense.

Tabela 2: Força de trabalho empregada na cotonicultura de Mato Grosso: $1980 / 1985$.

\begin{tabular}{l|c|c|c}
\hline Força de trabalho & $\mathbf{1 9 7 0}$ & $\mathbf{1 9 8 0}$ & $\mathbf{1 9 8 5}$ \\
\hline Homens adultos & 12.443 & 762 & 1.703 \\
Mulheres adultas & 6.333 & 388 & 867 \\
Menores de 14 anos & 7.415 & 454 & 1.014 \\
Pessoal ocupado & 26.191 & 1.604 & 3.584 \\
Área (hec.) & 105.700 & 6.127 & 15.000 \\
Hectare/trabalhador & $\mathbf{4 , 0}$ & $\mathbf{3 , 8}$ & $\mathbf{4 , 2}$ \\
\hline
\end{tabular}

Fonte: IBGE, Censos Agropecuários de 1970, 1980 e 1985.

Observando a força de trabalho empregada na cotonicultura em 1970 e 1980 pode-se ter clareza do enorme valor-trabalho incorporado nos fardos de algodão. Em 1970 havia mais de 26 mil trabalhadores rurais empregados na cotonicultura, lavrando 105.700 hectares. Há uma baixa relação terra/trabalho, com apenas 4,0 hectares lavrados por uma unidade de trabalho humano. Considerando que em 1970 uma área cotonícola média era de 16 hectares, pode-se dizer que em cada unidade de produção havia aproximadamente 4 trabalhadores, entre adultos e menores de 14 anos. Apenas relembrando que nestas métricas estão agregados os dados dos atuais estados de Mato Grosso e Mato Grosso do Sul. Em 1980, agora observando exclusivamente Mato Grosso, havia 1.604 trabalhadores. que lavraram 6.127 hectares. A relação terra-trabalho permaneceu muito próxima daquela verificada em 1970, com 3,8 hectares por força de trabalho empregada. Em uma área média de 29 hectares foram necessárias 8 unidades de trabalho para cultivar algodão herbáceo.

Não há mudança estrutural na força produtiva entre os dois censos, indicando que o processo de modernização da agricultura não havia iniciado na cotonicultura mato-grossense. Em função da pequena escala de produção e da baixa relação terra-trabalho, pode-se dizer que o emprego de tecnologia que eleva a composição orgânica do capital se apresentava incipiente e, como corolário, o capital variável e seu conhecimento difuso e ancestral permanecem 
como principal meio de produção. O trabalho é o pilar fundamental que sustenta a geração de pluma de algodão em Mato Grosso até este período. A composição técnica envolve elevado esforço humano e as condições sociais médias indicam uma elevada incorporação de trabalho por unidade de mercadoria produzida. Nestas condições, o capital agrário não é atraído por este setor produtivo como lócus de acumulação de capital e não há tensão no sistema para rebaixar o tempo de trabalho social. Portanto, não há movimento de redução do valor da mercadoria e não há pressão pela geração de renda diferencial do tipo II derivada de aplicação de novos métodos de trabalho (MARX, 1983). Nestas circunstâncias, o campesinato busca a sua acomodação estrutural na interface entre suas necessidades de reprodução social e as condições médias de produção e preço.

Como não havia cultivar adaptada à mecanização, a dependência de força de trabalho para todas as fases do cultivo delineava um sistema de elevada incorporação de valor-trabalho que garantia a superioridade do empreendimento camponês na cotonicultura, pois o capital agrário não produziria com preço de produção abaixo do preço de mercado. Por outro lado, somente o campesinato se ajusta a esta especificidade de sobreviver no sistema capitalista produzindo com valor acima do preço, redistribuindo seu excedente de forma difusa pela sociedade. O que acontece, portanto, é a aceitação tácita da eficiência orientada por outros indicadores técnicos, sociais e psicológicos que não a taxa objetiva de acumulação de capital. A ausência do capital agrário leva à conclusão de que a dinâmica interna do modelo produtivo cotonícola em Mato Grosso se orientava pela eficiência reprodutiva das famílias camponesas (COSTA, 2000) e não pela taxa de acumulação de capital. A necessidade latente de elevação do capital constante e da produção por unidade de meio de produção (seja a terra, o trabalho ou capital) não havia se implantado, ao menos na velocidade que os capitais imprimem a estas mudanças estruturais.

Note-se que nos censos de 1940/1950/1960/1970 a produtividade da terra registrada havia sido de 620/1.250/945/1.006 quilos por hectare, respectivamente em Mato Grosso. Quando os dados passam a registrar apenas a porção Setentrional do Mato Grosso, as médias de produtividade caem para 230 quilos em 1979 e 223 quilos em 1980, indicando que a produtividade dos censos anteriores a 1980 apresentavam uma enorme participação da área ao extremo sul do estado, na divisa com o estado do Paraná. A maior produtividade verificada neste espaço tensionava a média global a níveis muito superiores aos verificados na porção ao Norte e encobria uma baixa produtividade da terra. O que se quer dizer é que a força produtiva da cotonicultura na porção Setentrional de Mato 
Grosso apresentava-se bastante inferior à força produtiva vigente na porção Sul, revelando um maior esforço para gerar a mesma quantidade de mercadoria e um valor-trabalho incorporado nos fardos de pluma em níveis superiores à média regional.

Em 1970, foram produzidas 4,06 toneladas de algodão em caroço por trabalhador no espaço compreendido pelos atuais estados de Mato Grosso e Mato Grosso do Sul, contra apenas 0,9 tonelada em 1980, considerando apenas o atual Mato Grosso. Como em 1970 mais de 94\% da área plantada refere-se ao Mato Grosso do Sul, infere-se que a maior produtividade verificada neste censo deve-se à produção realizada na região Meridional e não aquela registrada na região de Rondonópolis. Muito provavelmente a produtividade da terra e do trabalho da cotonicultura no atual Mato Grosso permaneceu muito baixa desde a sua implantação até a década de 1980.

Em função desta baixa produtividade da cotonicultura verificada até 1980, foram realizados os primeiros trabalhos de pesquisa em Mato Grosso com 20 materiais genéticos na safra de 1984, testando época de plantio, competição de variedades e adubação, contando com o apoio da EMBRAPA (PROALMAT, 2007). Pela primeira vez a cotonicultura camponesa mato-grossense foi alvo de política pública específica, com a alocação de recursos orientados a elevar a capacidade produtiva das pequenas unidades. Os resultados desta geração de conhecimento respeitando as condições específicas da região Setentrional de Mato Grosso garantiram informações relevantes para elevar a produtividade por unidade de área e reduzir o esforço do trabalho, principal variável dos meios de produção. Pode-se dizer que houve uma inovação institucional radical que veio a potencializar a força produtiva do ramo.

Os resultados positivos foram verificados de imediato no Censo Agropecuário de 1985, que registrou uma produtividade da terra de 1.370 quilos de algodão em caroço por hectare. Em relação a 1980, houve um incremento de 1.147 quilos de algodão por unidade de área. Verificou-se uma importante elevação da utilização de insumos industriais na cotonicultura que passam a compor os meios de produção na forma de matérias-auxiliares, movimento verificado em dados da safra de 1985. Dados do IBGE indicam que o consumo intermediário na cotonicultura se elevou de $10 \%$ do valor bruto da produção em 1980 para 25\% em 1985, demonstrando uma tendência de utilização de tecnologia relacionada a sementes de melhor qualidade, fertilizantes e agrotóxicos ${ }^{4}$ (IBGE, 1980); (IBGE, 1985). Como corolário, a participação do capital constante cresce

4 A composição orgânica do capital (COC) se elevou de 0,1 em 1980 para 0,25 em 1985 (FARIA, 2008). 
e percebe-se uma redução na formação do valor-trabalho incorporado pela redução do tempo de trabalho médio. Estes resultados sugerem de forma clara que investimento em tecnologia e mudanças no ambiente institucional, com a EMBRAPA privilegiando o empreendimento camponês, é possível elevar a força produtiva desta estrutura social e gerar elevação do excedente produzido. O modelo camponês pode ser eficiente economicamente e propício à utilização de novos métodos de trabalho se as instituições formatarem um arranjo que o contemple. O camponês não é, desta forma, avesso à tecnologia (COSTA, 2000); (FARIA, 2008).

Tabela 3: Áreas de cotonicultura no censo de 1985: Mato Grosso.

\begin{tabular}{l|c|c|c|c|c}
\hline \multirow{2}{*}{ Dados estruturais } & \multicolumn{6}{|c}{ Grupos de área (hectares) } \\
\cline { 2 - 7 } & $\mathbf{0} \dashv \mathbf{1 0}$ & $\mathbf{1 0}-\mathbf{1 0 0}$ & $\mathbf{1 0 0} \dashv \mathbf{1 . 0 0 0}$ & $\mathbf{1 . 0 0 0} \dashv \mathbf{1 0 . 0 0 0}$ & Total \\
\hline UPA (unidades) & 350 & 611 & 59 & - & 1.020 \\
\hline UPA (\%) & 34 & 60 & 6 & - & 1,00 \\
\hline Área (hec.) & 1.680 & 7.270 & 6.050 & - & 15.000 \\
\hline Áreas (\%) & 11 & 49 & 40 & - & 1,00 \\
\hline Área média (hectares) & $\mathbf{5}$ & $\mathbf{1 2}$ & $\mathbf{1 0 3}$ & - & $\mathbf{1 5}$ \\
\hline
\end{tabular}

Fonte: IBGE, Censo Agropecuário de 1985.

A melhoria da composição técnica de produção foi combinada com favoráveis condições macroeconômicas para a cotonicultura brasileira em 1985, que seria a maior safra nacional em três décadas (1970-2000), com Mato Grosso elevando sua participação na produção de 0,12\% em 1980 para 0,94\% em 1985. O número de estabelecimentos onde a cotonicultura passou a ser a atividade principal no agrário mato-grossense elevou-se de 211 em 1980 para 1.020 em 1985, adicionando 809 famílias camponesas a esta atividade. A grande expansão ocorreu nos estratos de área inferiores a 100 hectares. Os micros produtores, com média de 5 hectares, elevaram-se de 98 unidades em 1980 para 350 unidades em 1985. Eles representavam 46\% dos estabelecimentos em 1980 e recuaram para 34\% em 1985. A área total controlada por este grupo sobe de $8 \%$ para $11 \%$. Os pequenos produtores, com áreas médias de 12 hectares, crescerem de 102 estabelecimentos para 611, representando 60\% das unidades de produção cotonícolas em 1985, contra 48\% em 1980. Controlavam 54\% da área em 1980 e caíram para 49\% em 1985. Agregando estes dois grupos de produtores (micro e pequenos), eles respondiam por $94 \%$ do total de estabelecimentos, com $60 \%$ da área total. Em 1980 eles controlavam 62\% da área e respondiam por 94\% dos estabelecimentos. Pode-se dizer que há uma relativa estabilidade na estrutura 
agrária destinada à cotonicultura em Mato Grosso entre as safras de 1980 e 1985, porém, com forte expansão das unidades produtivas e da área total da cotonicultura.

As áreas de lavouras entre 100 e 1.000 hectares subiram de 11 estabelecimentos em 1980 para 59 estabelecimentos em 1985, com forte redução da área média, de 212 para 103 hectares. Há uma redução da escala neste estrato de área, provavelmente relacionada à dificuldade de manejar grandes extensões com forte dependência da força de trabalho ou, por outro lado, com a significativa expansão da produtividade da terra em 1985 o ponto de equilíbrio econômico poderia ser alcançado com menor esforço absoluto objetivado em áreas de menor extensão cultivada. Este estrato continuou a representar 6\% dos estabelecimentos, mas fortaleceram sua área de produção em 2 pontos percentuais, ocupando 40\% da lavoura de algodão. Na safra de 1985 ainda não há registro de nenhuma lavoura com área superior a 1.000 hectares, o que corrobora com a hipótese de que o capital agrário ainda não havia selecionado a cotonicultura como lócus de acumulação de capital devido à dificuldade de garantir a produção homogênea com baixa dependência da força de trabalho. Até aquele momento, reitera-se, não há tecnologia disponível capaz de eliminar o conhecimento tácito dos trabalhadores diretos e sua habilidade em manejar as diversas fases do cultivo. Neste momento, ainda em menor grau do que o trabalho, o capital constante adentra à composição técnica de produção mais fortemente como matérias-auxiliares do que como máquinas e ferramentas que poderiam elevar a mesma composição técnica. Assim, não há redução direta do capital variável, mas a incorporação de matérias-auxiliares intensifica o uso da terra e eleva a produtividade do trabalho, com rebatimento na expansão da COC.

Percebe-se uma dispersão maior da cotonicultura pelo espaço matogrossense, com elevação da área na região Sudoeste, que passou a contar com 8.714 hectares, ou $58 \%$ da área total. Nesta região o município de Cáceres, dentro da Bacia do Alto Paraguai (BAP) tornou-se o principal espaço produtor, com 5.304 hectares (35\% do total). Especificamente os municípios de Mirassol D’Oeste (1.682 hectares) e São José dos Quatro Marcos (411 hectares), na mesma região Sudoeste, foram colonizados com direcionamento da base produtiva para a cotonicultura em pequena escala (MATO GROSSO, 2004). Em Tangará da Serra, ao Norte de Cáceres, foram cultivados 1.012 hectares, ou 7\% da área total.

A região Sudeste foi suporte para 5.334 hectares, ou $36 \%$ da área cotonícola. Em Rondonópolis foram cultivados 3.731 hectares (25\% da área total). No município de Pedra Preta foram cultivados 881 hectares em unidades de produção de base camponesa. Este região perde força relativa e mantém aproximadamente 
a mesma área verificada no Censo de 1980, o que leva à conclusão de que a expansão da área em quase 9.000 hectares entre 1980 e 1985 está relacionada ao fortalecimento da atividade na porção Sudoeste, notadamente em pequenas áreas de agricultura familiar. Se Rondonópolis ficou conhecida como a "Rainha do Algodão" até 1980, Cáceres poderia ter requisitado ao menos o título de "Princesa do Algodão" em 1985.

Além da nova configuração espacial, a grande mudança dentro do ramo produtivo após a geração e difusão da tecnologia cotonícola está relacionada com a importante elevação da produtividade do trabalho na safra de $1985 \mathrm{em}$ relação a 1980. Primeiro que na safra de 1985 cada trabalhador lavrou em média 4,2 hectares contra 3,8 em 1980. Este crescimento da força produtiva garantiu que uma redução do esforço médio de produzir, pois foram necessários menos braços para controlar a mesma unidade de área. A segunda mudança que elevou a produtividade do trabalho está atrelada à expansão da produtividade da terra, que havia sido de 223 quilos de algodão em caroço por hectare em $1980 \mathrm{e}$ alcançou 1.370 quilos em 1985. Este duplo movimento gerou uma produção de 5,7 toneladas de algodão em caroço por unidade trabalho, enquanto que na safra de 1980 havia sido de apenas 0,9 tonelada por trabalhador. Pode-se afirmar que há uma expressiva elevação da força produtiva do ramo cotonícola verificada em 1985. A produtividade da terra e do trabalho em relação à mercadoria final se eleva em mais de seis vezes, reduzindo o esforço humano médio cristalizado na mercadoria física.

Tabela 4: Produtividade da terra e do trabalho na cotonicultura de Mato Grosso.

\begin{tabular}{c|c|c|c|c|c}
\hline Safra & $\begin{array}{c}\text { Pessoal } \\
(\mathrm{I})\end{array}$ & $\begin{array}{c}\text { Produção } \\
(\text { Ton.) } \\
(\mathrm{II})\end{array}$ & $\begin{array}{c}\text { Área } \\
(\mathrm{Hec}) \\
(\mathrm{III})\end{array}$ & $\begin{array}{c}\text { Produtividade } \\
\text { Ton./Hectare } \\
(\mathrm{II} / \mathrm{III})\end{array}$ & $\begin{array}{c}\text { Produtividade Ton./ } \\
\text { Trabalhador } \\
(\mathrm{II} / \mathrm{I})\end{array}$ \\
\hline 1980 & 1.604 & 1.367 & 6.127 & 0,223 & 0,9 \\
\hline 1985 & 3.584 & 20.550 & 15.000 & 1.370 & 5,7 \\
\hline
\end{tabular}

Fonte: IBGE (1980), IBGE (1985).

A Tabela 4 e os Gráficos 1 e 2 resumem claramente este movimento de ruptura e mudança paradigmática. Em um curto período de tempo a cotonicultura regional foi impactada de forma radical a partir de um esforço institucional que permitiram ganhos de produtividade dentro do modelo camponês compatíveis com a necessidade de gerar excedentes comercializáveis na esfera da circulação. Com menos braços por área cultivada e maior tecnologia aplicada, o excedente gerado poderia, por um lado, se materializar em elevação das condições médias 
de reprodução social para os camponeses e, por outro lado, pela oferta crescente de matéria-prima para a indústria de beneficiamento e vestuário a preços declinantes. Este duplo caráter da melhoria da força produtiva do ramo cotonícola cumpriria dois grandes objetivos em relação ao desenvolvimento regional: (i) elevaria o padrão reprodutivo dos camponeses por um maior controle sobre o excedente gerado, potencializando a capacidade de consumo e investimento do empreendimento camponês; e (ii) tensionaria os preços de mercado do algodão em caroço a reduzirem pela melhoria das condições médias de produção, com rebatimento na capacidade competitiva das indústrias de transformação da pluma, podendo potencializar a agroindustrialização da fibra do algodoeiro dentro das fronteiras regionais.

Gráfico 1: Produtividade da terra na cotonicultura de Mato Grosso: 1980 e 1985.

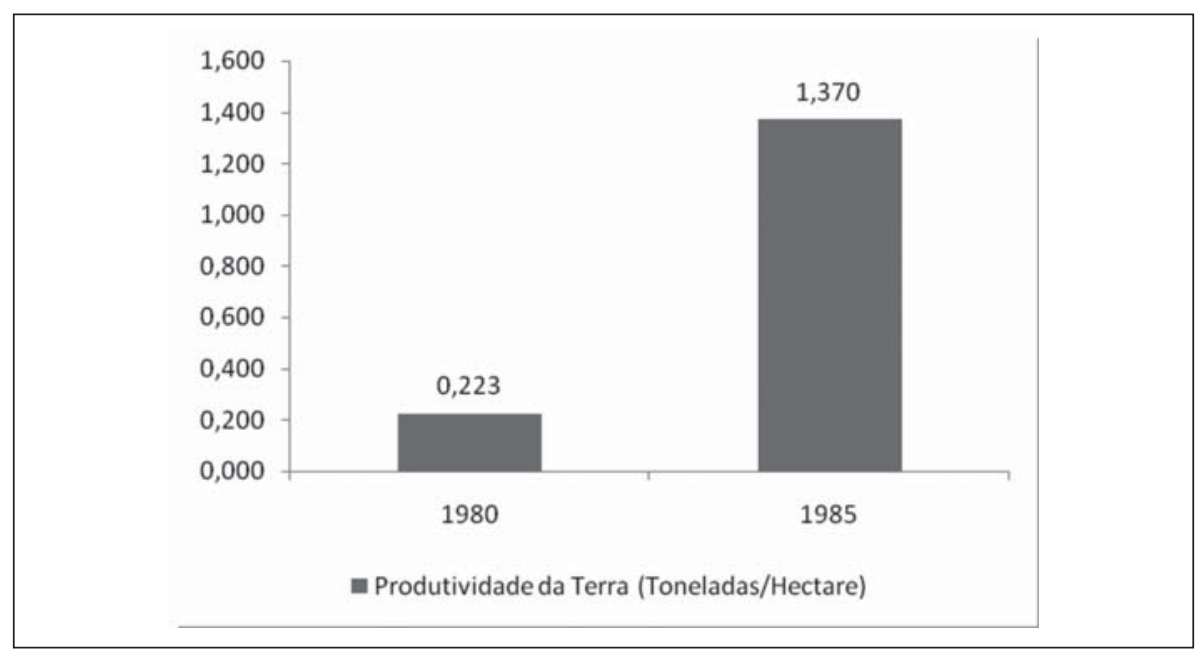

Um dos indicadores que revelam a melhoria das condições de produção e a tendência de redução do preço de produção é a expansão da COC que reduz o tempo médio de produção da mercadoria, que pode ser vista na Tabela 5. Os dados indicam a redução do trabalho equivalente de mais de mil horas por tonelada de algodão produzido em 1980 para apenas 150 horas de trabalho humano equivalente na safra de 1985. O forte crescimento da produtividade da terra e do trabalho a partir da inovação institucional da EMBRAPA de gerar e fornecer tecnologia específica ao modelo camponês garantiu uma forte ampliação da força produtiva do ramo cotonícola, demonstrando que este segmento sócioprodutivo não é avesso a incorporação de tecnologia, mas, pelo contrário, responde rapidamente ao estímulo de produção excedente. 
Tabela 5: Horas homem-equivalente/tonelada na cotonicultura de Mato Grosso.

\begin{tabular}{c|c|c|c|c}
\hline Safra & COC & $\begin{array}{c}\text { HHE total } \\
\text { (horas) } \\
\text { (I) }\end{array}$ & $\begin{array}{c}\text { Produção (ton.) } \\
\text { (II) }\end{array}$ & $\begin{array}{c}\text { Trabalhador- } \\
\text { equivalente/tonelada } \\
\text { (I/II) }\end{array}$ \\
\hline 1980 & 0,10 & $1.377 * 10^{3}$ & 1.367 & 1.007 \\
\hline 1985 & 0,25 & $3.077 * 10^{3}$ & 20.550 & 150 \\
\hline
\end{tabular}

Fonte: Elaborada pelo autor a partir de IBGE (1980) e IBGE (1985).

Nota: o método de conversão de trabalho específico em geral pode ser visto de forma detalhada em Faria (2008).

Gráfico 2: Produtividade do trabalho na cotonicultura de Mato Grosso: 1980 e 1985.

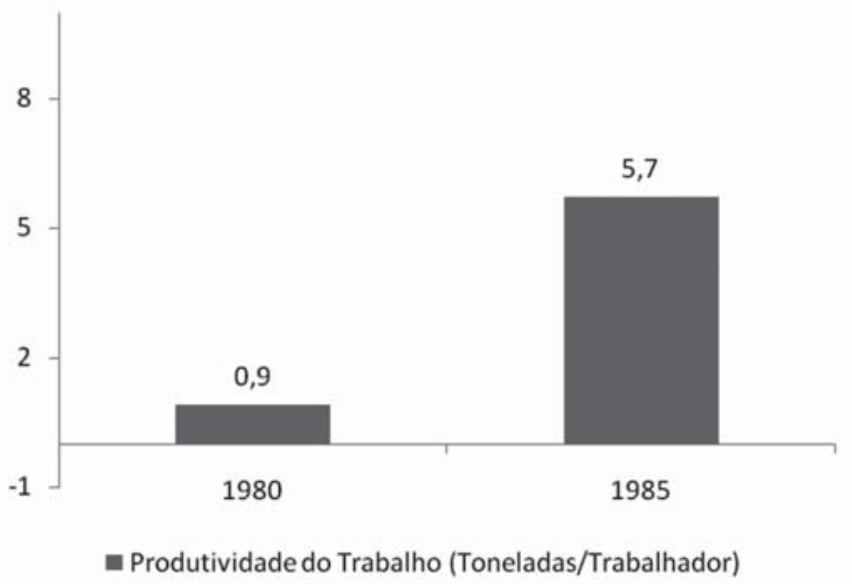

O crescimento de 211 famílias produtoras em 1980 para 1.020 famílias em 1985, bem como a força de trabalho ocupada na cotonicultura de 1.604 trabalhadores em 1980 para 3.584 em 1985 estão diretamente relacionados ao processo de intensificação e elevação da força produtiva do ramo cotonícola neste período. Os dados que indicam a melhoria da eficiência reprodutiva dos camponeses pode ser visto na Tabela 6. Apesar da receita por estabelecimento ter reduzido em valores reais entre as duas safras, o valor bruto da produção por hectare se expandiu em $76 \%$ no período, além do valor adicionado bruto ter crescido em 55\%. A grande dilatação ocorreu no consumo intermediário, que expandiu em 273\% em termos reais entre 1980 e 1985, demonstrando que a incorporação de tecnologia pode alterar significativamente a posição relativa de empreendimentos camponeses na interface entre as esferas da produção e da circulação. 
Observe-se que os preços reais da tonelada de pluma sofreram um importante revés, caindo de 4,5 mil reais para 1,3 mil reais entre as duas safras ${ }^{5}$. Aqui está uma grande contribuição da difusão de tecnologia ao processo de desenvolvimento regional. O preço real de produção da tonelada comercializada pelos camponeses foi reduzido em $71 \%$ em apenas cinco safras, um corte de 3,2 mil reais por tonelada de algodão em função da elevação da força produtiva. Para as indústrias que utilizam a fibra do algodão como matéria-prima, este resultado indica uma renovada capacidade de competição e retenção de valores-trabalho na esfera da circulação, pois os ganhos de produtividade do setor primários são repassados ao setor industrial como redução do custo de produção. Caso os preços na esfera da circulação forem rebaixados proporcionalmente à queda no setor primário os ganhos sociais agregados se tornam difusos, pois a sociedade estará demando uma mercadoria a preços decrescentes e haverá a formação de um excedente que poderá ser alocado em outras demandas, impulsionando diversos ramos produtivos a partir da elevação da eficiência do ramo cotonícola, que passou a ser remunerado por menores preços individuais.

Tabela 6: Indicadores econômicos e sociais de produção e apropriação do excedente na cotonicultura de Mato Grosso, deflacionado a preços de 1996 (em reais).

\begin{tabular}{l|r|r}
\hline Indicadores & \multicolumn{1}{|c|}{$\mathbf{1 9 8 0}$} & \multicolumn{1}{|c}{$\mathbf{1 9 8 5}$} \\
\hline Receita/estabelecimento & $10.608,43$ & $9.441,97$ \\
VBP/hectare & 365,33 & 642,05 \\
CI/hectare & 34,47 & 128,41 \\
VAB/hectare & 330,87 & 513,64 \\
VBP/tonelada de pluma & $4.549,55$ & $1.301,46$ \\
CI/tonelada de pluma & 429,20 & 260,29 \\
VAB/tonelada de pluma & $4.120,35$ & $1.041,17$ \\
VAB/estabelecimento & $9.607,63$ & $7.553,58$ \\
VAB/trabalhador & $1.263,85$ & $2.149,74$ \\
Excedente/trabalhador & 921,55 & $1.701,87$ \\
Excedente mensal/estabelecimento & 583,80 & 498,33 \\
Salário mínimo (SM) vigente & 169,66 & 103,40 \\
Excedente mensal/UPA (em SM) & 3,44 & 4,82 \\
Trabalhadores familiares/UPA (unidade) & 7,6 & 3,5 \\
Renda/trabalhador familiar (em SM) & 0,5 & 1,4 \\
\hline
\end{tabular}

Fonte: FARIA (2008).

Nota: (i) VBP indica o Valor Bruto da Produção; (ii) CI indica o Consumo Intermediário; (iii) VAB indica o Valor Adicionado Bruto; e SM indica salários mínimos vigentes.

\footnotetext{
5 A moeda corrente no período 1980-1985 era o cruzeiro (Cr\$). Utilizando a unidade real de valor (URV) como referência, o valor da produção de 1980 e 1985 foi transformado para a moeda corrente em 1996, o real (R\$). Depois, foi aplicado o IGP-DI (índice geral de preços, disponibilidade interna) com base em dezembro de 1996 como deflator para homogeneizar a série de dados.
} 
Mesmo os camponeses recebendo preços reais por tonelada $71 \%$ inferiores na safra de 1985 em relação a 1980, a ampliação da produtividade da terra elevou a produção por hectare, garantindo que a receita total média por estabelecimento em 1985 fosse muito próxima de 1980. Os principais resultados econômicos indicam uma melhoria substancial do modelo camponês em reter o excedente ao seu favor, pois o valor adicionado por trabalhador cresceu de 1,2 mil reais para 2,1 mil reais entre as duas safras. Descontando o pagamento de salários para trabalhadores externos, o excedente apropriado por trabalhadores da própria família camponesa subiu de 0,9 mil reais anuais em 1980 para 1,7 mil reais anuais em 1985, um crescimento real de $89 \%$ no período.

Apesar do excedente mensal por estabelecimento ter recuado de 583 reais para 498 reais no período analisado, as condições de retenção do excedente conduziram as famílias camponesas produtoras de algodão a uma melhoria relativa em termos sociais, pois passaram a controlar 4,82 salários mínimos mensais em 1985 contra 3,44 salários mínimos mensais em 1980. Esta relação é central para identificar a interface entre o sistema camponês e a sociedade, pois o salário mínimo vigente é a referência da força de trabalho em relação a outras atividades produtivas similares. Enquanto em 1980 cada membro da família camponesa conseguia reter 0,5 salário mínimo a cada mês, em 1985 cada membro reteve 1,4 salário mínimo por mês. As condições de reprodução social se elevaram de forma vigorosa em termos reais, com expansão de 2,8 vezes a capacidade de comprar trabalho abstrato alheio, objetivado em unidades monetárias geradas na cotonicultura.

Os dados da Tabela 6 indicam que a geração e difusão da tecnologia cotonícola garantiram uma condição econômica e social diferenciadas na safra de 1985 em relação a 1980 capazes de incluir 809 famílias e 1.980 trabalhadores diretos $^{6}$. Esta incorporação de novos cotonicultores revelou uma política pública eficiente em termos sociais e econômicos, objetivada em uma estratégia de geração e retenção do excedente para os camponeses e ao mesmo tempo redução do preço médio real de comercialização em $71 \%$ para as indústrias de transformação. Além disso, a oferta de pluma cresceu de 1,3 toneladas em 1980 para 20,5 toneladas em 1985, ampliação de quase $1.500 \%$, demonstrando a capacidade de resposta do campesinato em garantir a expansão da oferta real da mercadoria. Depreende-se deste fato que não se pode desprezar o modelo camponês como lócus do desenvolvimento regional, tanto (i) pela capacidade

Caso seja estimado o impacto indireto da produção de algodão em caroço, pode-se dizer que foram gerados outros 2.812 empregos em setores direta e indiretamente relacionados (FARIA; PEREIRA; BEDIN, 2007), com impacto total de 4.792 trabalhadores incorporados ao processo produtivo a partir da inovação institucional da EMBRAPA. 
de ofertar matéria-prima às indústrias, quanto (ii) pela capacidade de reduzir o preço de produção e (iii) distribuir renda de forma direta ou difusa para elevar a capacidade de consumo regional.

Contudo, a partir de 1989 a EMBRAPA passou a pesquisar materiais genéticos e novas formas de manejo para a cotonicultura mato-grossense dentro do modelo patronal, privilegiando o grande empreendimento capitalista com elevada mecanização e utilização de pacotes tecnológicos forâneos adaptados às condições regionais. A grande inovação tecnológica ocorreu em 1991 a partir do convênio da EMBRAPA com o grupo empresarial Itamarati Norte, gerando a nova cultivar CNPA-ITA 90 totalmente adaptada à mecanização e às condições edafoclimáticas regionais. Após um período de aprendizado dinâmico por parte dos patronais, em 1997 foi criado o PROALMAT ${ }^{7}$, um programa de incentivos fiscais que reduziram a carga tributária da cotonicultura em 75\%. Os camponeses não foram excluídos da possibilidade de acessar o programa de incentivos, mas a tecnologia e as novas formas de gestão são fortes barreiras que dificultam o acesso do empreendimento camponês na nova cotonicultura empresarial, tanto que na safra de 2006 não houve registro de áreas cotonícolas inferiores a 100 hectares em Mato Grosso (FARIA, 2003); (FARIA e CAMPOS, 2006); (FARIA, 2008).

Uma questão de fundo refere-se ao impacto econômico, social e ambiental do novo modelo produtivo baseado no capital e não nas famílias rurais. Apesar de ter gerado um forte impulso no valor bruto da produção mato-grossense, o modelo atual pautado em áreas médias acima de 2.800 hectares não gera efeitos indiretos sobre o emprego regional (pois $98 \%$ da produção são enviadas como matéria-prima para fora do estado), apresenta-se como um mecanismo de concentração de renda e de produção, além de impactos ambientais relevantes como perda de biodiversidade faunística e florística, contaminação do solo, da água e do ar por agrotóxicos, erosão eólica e pluvial e de compactação do solo que dificulta a resiliência do ecossistema regional. Ademais, ao substituir mais de 1.000 famílias produzindo em áreas médias inferiores a 30 hectares por pouco mais de uma centena de grandes cotonicultores com áreas acima de 2.800 hectares, o modelo de desenvolvimento regional pauta-se pelo excesso de incentivo à produção capitalista e por negligenciar uma política de difusão do conhecimento e fortalecimento social de milhares de famílias camponesas que poderiam responder às necessidades da indústria com quanto à qualidade e preço tecendo um robusto tecido social (FARIA, 2003); (FARIA, 2008).

Programa de Incentivo ao Algodão de Mato Grosso, conforme as Leis Estaduais n. ${ }^{\circ}$ 6.883/97 e 7.751/2002 [(MATO GROSSO, 1997); (MATO GROSSO, 2002)]. 


\section{CONCLUSÕES}

A produção de algodão em Mato Grosso até 1980 foi conduzida por empreendimentos familiares em áreas médias inferiores a 30 hectares, com reduzida produtividade da terra e do trabalho. A priori, poder-se-ia concluir de forma superficial que o modelo camponês é ineficiente do ponto de vista tecnológico e econômico. A inovação institucional da EMBRAPA na safra de 1984, pesquisando novos métodos de gestão e cultivares adaptadas às condições edafoclimáticas regionais viria a desmistificar a incapacidade do campesinato em responder à elevação da produção, da produtividade e da geração e retenção do excedente conjugado com uma forte redução do preço de produção.

Os dados da safra de 1985 indicam uma expansão da produtividade da terra de forma exponencial, alcançado 1.370 toneladas por hectare frente a 0,223 toneladas em 1980. A relação terra-trabalho elevou-se de 3,8 hectares em 1980 para 4,2 hectares em 1985. A produtividade do trabalho dilatou-se de 0,9 toneladas de algodão por trabalhador em 1980 para 5,7 toneladas em 1985. O excedente bruto por trabalhador saltou de 0,9 mil reais para 1,7 mil reais entre as duas safras. E o salário mínimo mensal retido por trabalhador cresceu de 0,5 em 1980 para 1,4 em 1985 dentro do modelo familiar. Como resultado da melhoria da força produtiva do ramo cotonícola após os esforços institucionais da EMBRAPA, o número de empreendimentos camponeses que produziram algodão dilatou-se de 211 para 1.020 entre 1980 e 1985. O impacto social na geração de empregos e na formação e retenção de renda no ramo foi significativo, com inclusão de aproximadamente 4.800 trabalhadores diretamente no ramo ou em ramos relacionados.

Do ponto de vista econômico, os novos conhecimentos e a aplicação de tecnologia permitiu a redução do preço de produção de 4,5 mil reais por tonelada em 1980 para 1,3 mil reais por tonelada em 1985, demonstrando uma forte capacidade de elevar a eficiência sistêmica de todos os elos da indústria de transformação que utilizam o algodão como matéria-prima direta ou indireta. O rebatimento na esfera da circulação do algodão ocorre na esfera da produção dos ramos industriais relacionados, gerando melhores condições concorrenciais pela redução do custo de produção. Ademais, o declínio dos preços médios no setor primário pode, caso não haja forte concentração de mercado, se refletir na esfera da circulação das mercadorias finais, gerando um excedente capaz de ser realocado em outras mercadorias elevando o consumo agregado na economia. Assim, pode-se dizer em distribuição difusa de renda pela redução do preço de produção no modelo camponês. 
Após recuperar o grande resultado da ação institucional da EMBRAPA, o objetivo deste trabalho foi recolocar no debate a capacidade de resposta do modelo camponês dentro do sistema capitalista. Os resultados são claros, o camponês não é avesso à tecnologia e pode constituir em uma estrutura sócioprodutiva estratégica para o desenvolvimento regional em função de sua elevada capacidade de gerar excedentes que podem ser controlados endogenamente para elevar seu padrão reprodutivo e ao mesmo tempo reduzir os preços de produção com rebatimentos sociais relevantes de forma difusa. Não se afirma que o modelo patronal não deva ser incentivado, mas que o modelo camponês de forma alguma é incapaz de acessar tecnologia e responder de forma ineficiente e que, portanto, não deve ser negligenciado. O PROALMAT não contempla esforços concatenados de forma específica para garantir a eficiência das estruturas familiares, o que tem impedido uma trajetória mais equitativa do progresso técnico e econômico dos dois modelos produtivos. Esta incapacidade é uma perda institucional relevante.

Os camponeses podem e devem compor o núcleo duro de inovações tecnológicas como na ação da EMBRAPA em 1984, pois o modelo agrário brasileiro e mato-grossense é dual, contempla estruturas patronais e camponesas e os incentivos institucionais devem manter o equilíbrio na distribuição das ações e dos recursos entre as duas. Ademais, se a meta é o desenvolvimento social atrelado ao desenvolvimento econômico de uma região, o modelo camponês tem demonstrado sua superioridade em distribuir renda direta e difusa em relação aos patronais. Não é uma questão ideológica, mas de eficiência.

\section{REFERÊNCIAS}

COMPANHIA NACIONAL DE ABASTECIMENTO. Indicadores da Agropecuária. Disponível em: www.conab.gov.br. Acesso em: 20 dez. 2005.

COSTA, F. A. Formação agropecuária da Amazônia: os desafios do desenvolvimento sustentável. Belém: UFPA-NAEA, 2000.

FARIA, A. M. M. Destramando o tecido do desenvolvimento: do campesinato à hegemonia do capital agrário na cotonicultura de Mato Grosso. 2008. 326 f. Tese (Doutorado em Desenvolvimento Sustentável do Trópico Úmido) - Núcleo de Altos Estudos Amazônicos, Universidade Federal do Pará, Belém, 2008.

A expansão da cotonicultura em Mato Grosso na década de 1990: um caso paradigmático de desenvolvimento endógeno. 2003. 143 f. Dissertação (Mestrado em Planejamento do Desenvolvimento) - Núcleo de Altos Estudos Amazônicos, Universidade Federal do Pará, Belém, 2003. 
FARIA, A. M. M.; CAMPOS, I. Determinantes da concentração da cotonicultura na Amazônia Legal. Papers do NAEA, n. 189, 2006. Disponível em: www.ufpa. $\mathrm{br} /$ naea.

FARIA, A. M. M.; PEREIRA, B. D.; BEDIN, S. L. Avaliação dos Incentivos Fiscais da Cotonicultura em Mato Grosso e Análise dos Seus Impactos na Estrutura Sócio-econômica Regional. Relatório de Pesquisa. Cuiabá, UFMTIMA (Instituto Mato-Grossense do Algodão), ago. 2007.

IBGE. Censo Agropecuário de Mato Grosso: 1985. Rio de Janeiro, 1985.

Censo Agropecuário de Mato Grosso: 1980. Rio de Janeiro, 1980. Censo Agropecuário de Mato Grosso: 1960. Rio de Janeiro, 1970. Censo Agropecuário de Mato Grosso: 1960. Rio de Janeiro, 1960. Censo Agropecuário de Mato Grosso: 1950. Rio de Janeiro, 1950. Censo Agropecuário de Mato Grosso: 1940. Rio de Janeiro, 1940.

MARX, K. O Capital. Livro III, v. VI. São Paulo: Difel, 1983.

MATO GROSSO. Lei Estadual n. 6.883, de 02 de junho de 1997, que institui o Programa de Incentivo à Cultura do Algodão de Mato Grosso - PROALMAT e cria o Fundo de Apoio à Cultura do Algodão - FACUAL. Diário Oficial de Mato Grosso, Cuiabá, 02.06.1997.

Lei Estadual n. ${ }^{\circ}$ 7.751, de 14 de novembro de 2002, altera dispositivos da Lei n. 6.883, de 02 de junho de 1997, prorroga o prazo de vigência do PROALMAT e dá outras providências. Diário Oficial de Mato Grosso, Cuiabá, 14.11.2002.

Secretaria de Estado de Planejamento e Coordenação Geral. Superintendência de Informações. Zoneamento Sócio Econômico Ecológico do Estado de Mato Grosso. Cuiabá, jul. 2004.

PROGRAMA DE INCENTIVO À CULTURA DO ALGODÃO DE MATO GROSSO. Lavouras Cadastradas: safras 1998-2003. Disponível em: www. proalmat.mt.gov.br. Acesso em: 8 jan. 2007. 